\title{
Psychiatric Morbidity and Stressful Life Events in Elderly -A Hospital Based Cross-Sectional Study
}

\author{
Shyama Krishnan ${ }^{1}$, Sumesh Balachandran², Yesudas K. F. ${ }^{3}$ \\ ${ }^{1}$ Department of Psychiatry, Government Medical College, Kannur, Kerala, India. ${ }^{2}$ Department of Psychiatry, \\ Government Medical College, Kannur, Kerala, India. ${ }^{3}$ Department of Psychiatry, Government Medical College, Kannur, \\ Kerala, India.
}

\section{ABSTRACT}

\section{BACKGROUND}

There has been increasing prevalence of mental health problems in the elderly, with stressful life events being a precipitating factor and hence impairing the quality of life.

\section{METHODS}

263 patients of age 60 years and above attending psychiatry outpatient department and admitted in medical wards were included in the study. Patients with MMSE score $\geq 24$ were included in the study. MINI PLUS was used to assess the psychiatric morbidity. Life events were assessed by PSLES. Statistical analysis was done using SPSS. Descriptive statistics and chi-square test were used for analysis.

\section{RESULTS}

Out of 263 patients, $207(78.7 \%)$ were in the age group 60-69 yrs. The common psychiatric morbidity was found to be depression (43\%), substance use disorders $(16.7 \%)$ and anxiety spectrum disorders $(15.5 \%)$. The most common precipitating stressful life events were family conflict $(9.5 \%)$, son or daughter leaving home $(8.7 \%)$, death of spouse $(6.5 \%)$ and financial loss $(6.5 \%)$. The common psychiatric morbidity precipitated by stressful life events were depression $(44.4 \%)$ and substance use (18.2\%) followed by anxiety and stress related disorders $(22.2 \%)$.

\section{CONCLUSIONS}

The above study emphasizes that psychiatric morbidity is common in the geriatric population, of which depression is the most common mental health problem. Stressful life events can lead to mental health problems. These factors impair the quality of life of the elderly. Hence it necessitates psychiatrists and physicians to recognize mental health problems at the earliest and provide the necessary support to improve the quality of life.

\section{KEY WORDS}

Psychiatric Morbidity, Stressful Life Events, Geriatric Population
Corresponding Author:

Dr. Yesudas K. F.,

Professor and HOD,

Department of Psychiatry, Government Medical College,

Kannur, Kalathara House,

Payyanur, Kerala, India.

E-mail:dr.yesudaskf@gmail.com

DOI: $10.14260 /$ jemds $/ 2020 / 6$

Financial or Other Competing Interests: None.

How to Cite This Article:

Krishnan S, Balachandran S, Yesudas KF. Psychiatric morbidity and stressful life events in elderly-a hospital based crosssectional study. J. Evolution Med. Dent. Sci. 2020;9(01):23-28, DOI:
Submission 08-11-2019,

Peer Review 21-12-2019,

Acceptance 27-12-2019,

Published 06-01-2020. 


\section{BACKGROUND}

As per United Nations, a country is considered as 'ageing', when the proportion of people aged more than 60 years reaches $7 \%$. Accordingly, India is considered as an ageing nation and in the coming years it will result in 316 million elderly persons by $2050 . .^{1}$ This emphasizes the importance to study the life events before the onset of psychiatric illness in elderly. Most hospitals in the country do not have specialized facilities to cater to the needs of geriatric population. It is found that lack of priority given to the healthcare needs of the elderly is the major factor for the low level of public awareness about mental health problems of old age. ${ }^{2}$ The feeling of loneliness along with the natural age-related incapacity in the physical and physiological functioning make the elderly more prone to psychological disturbances. ${ }^{3}$ Hence, dependency is common among elderly people and many may need assistance in their activities of daily living. Katon and Sullivan et al. (1990)also found that $6 \%$ of the patients in primary care setting and $11 \%$ of medical in-patients had major depression, compared with $3 \%$ prevalence in general population. ${ }^{4}$ As perKatz and Alexopoules et al. (1996),many of the depressive disorders remain undiagnosed and untreated as the general population considers it to be a normal part of ageing. ${ }^{5}$ Uwake et al. (2000) who evaluated all the patients aged more than 60 years admitted in nonpsychiatric wards in a teaching hospital and found that $45.3 \%$ of the patients had psychiatric illness, with depression being the commonest, followed by organic disorders, adjustment disorder, and generalized anxiety disorder. But, only $2.8 \%$ of the mental disorders could be recognized by the physicians. ${ }^{6}$ This emphasizes the need for psychiatric assessment to be an integral part of complete health assessment of geriatric patients. Depression in older men frequently presents with anxious or irritable mood and restlessness or agitation (Lenze et al., 2000). ${ }^{7}$ The elderly are at a higher risk for suicide than other groups and is associated with severity of depressive illness, Henceit is essential to ask both about affective symptoms and actual suicidal ideation (Raue et al., 2001). ${ }^{8}$

A single institutional retrospective study of 3 years was conducted by Singh GP et al. (2004). Results showed that mood disorders (48.7\%), neurotic, stress-related and somatoform disorders (15.47\%) were the most common psychiatric disorders in these patients. Medical comorbidity was a significant finding of this study as physical diagnosis was present in most of these patients (56.35\%). ${ }^{9}$

The age-specific suicide rates increase with advanced age. Hanging and poisoning were found to be the common methods of suicide by elderly (Abraham et al., 2005). ${ }^{10}$ Similar finding was also found in the study by Behera et al. (2007). ${ }^{11}$ Depression is the leading cause for suicide, and nearly two-thirds of depressed elderly had suicide ideation (Venkoba Rao and Madhavan et al., 1983) ${ }^{12}$ and the most important predictor was lack of family and social integration rather than 'living alone'. Ethical, religious and familial factors [described as suicide counters by Venkoba Rao (1985)] may prevent the elderly from attempting suicide. ${ }^{13}$ Suicides in elderly are often associated with high intent, long planning and highly lethal methods.
With respect to substance use among rural elderly, the prevalence of smoking is 51-71.8\% among males and 5-41 $\%$ among females (Goswami et al., 2005; Jotheeswaran et al., 2010; Shaji et al., 2002). ${ }^{14,15,16}$ According to a large-scale population study, the current use of alcohol varied between 10 and $28 \%$ among 50 years plus age groups and majority were current heavy users (Mohan et al. 2002; Gupta et al. 2003). ${ }^{17,18}$ Recent studies from Lucknow which are supported by Indian Council of Medical Research (ICMR), found that $17.3 \%$ of rural elderly and $23.5 \%$ of urban elderly suffer from a psychiatric illness (Tiwari et al., 2012; Seby et al., 2011). ${ }^{19,20}$ Depression was common among elderly who visit the general health settings and those staying in old age homes (Dey et al. 2001; Tiwari et al. 2012 Ganguli et al. 1999).21,19,22 Studies show that the prevalence rates of depression in elderly are considerably higher than the general population rates in India (Reddy and Chandrashekhar et al., 1998; Poongothai et al., 2009).23,24 According to Barua et al (2010) one of the two non-modifiable risk factors for elderly depression are female gender and advanced age. Other factors known to increase the likelihood of depression are illiteracy, financial difficulties, living alone, low social/emotional support, widowhood, economic or physical dependency and presence of chronic physical illnesses or disability of any kind. ${ }^{25}$ Hence these factors are considered as stressful life events capable of precipitating psychiatric illness. A comparative study by Tiple et al (2006) found that the people living in old age homes had better supportive care than those living with the families. ${ }^{26}$ According to $0 \mathrm{~m}$ Prakash et al (2007) out of one hundred medically ill elderly ( $>60$ years) patients attending the Geriatric Clinic at Bikaner (North India), 18\% subjects had depression and 11\% had other mental disorders. Those having mental disorders had suffered more recent stressful life events. In this study, the most reported stressful life events were conflicts in family (16\%); unemployment of self or children (9\%). Other reported life events were illness of self $(6 \%)$ or family members $(5 \%)$ and death of family members $(5 \%)$ or close relatives (4\%). Also, hypertension was the most commonly reported physical diagnosis (50\%), other specific medical illnesses were osteoarthritis (15\%), diabetes (13\%) and constipation $(8 \%)$

A cross-sectional study was done to assess depression over 473 elderly persons from an urban slum in Bangalore (2014). The result showed that the prevalence of depression to be $37.8 \%$. Also multivariate analysis of life events revealed that unemployment (self or children) was commonest stressful life event, followed by illness of self, female gender, conflicts in family, and marriage of children or grandchildren as independent risk factors. ${ }^{27}$ The effect of socioeconomic parameters with respect to life events experienced by the elderly depressed is not reported much in the literature. There is possibility that those with low 'per capita income' are more prone to experience life events.

As per Venkoba Rao et al (1981) stressors related to 'bereavement', 'occupation' and 'family and social relationships' in the 2 years preceding onset of depression were significant precipitating factors. Living in joint families need not guarantee a good social integration, as old ones in family can be 'lonely islands'. ${ }^{28}$ 
Niruj et al (2002) following analysis of the study found that most patients had mild (48.4\%) or moderate (41.9\%) depression and also importantly found that the severity of depression was not associated with significantly higher life events. This study emphasizes that the life events are associated with occurrence of depression and not its severity, which is in consonance with the existing literature. ${ }^{29}$

We wanted to assess the geriatric psychiatric morbidity and the presence of stressful life events in elderly with psychiatric morbidity.

\section{METHODS}

The study was conducted after obtaining ethical committee clearance which was conducted in the institute. The study will be done on those patients who agrees upon the informed consent provided to them. A cross-sectional study of geriatric outpatients of department of psychiatry and inpatients of medical wards of GMC, Kannur were done. The study period was from March 2018 to February 2019. A consecutive sample of 334 patients who satisfy the inclusion criteria was recruited for the study. (sample size is calculated using formula: $4 \mathrm{pq} / \mathrm{d}^{2}$ with an assumed prevalence of $29.8 \%{ }^{26}$ depression in geriatric population and a precision factor of 5 , $p$-prevalence, $q=100-p$ and $d$ is precision factor). The inclusion criteria were patients of either gender aged 60 years or above attending psychiatric OPD and those hospitalized in wards of GMC, Kannur, those patients willing to give written informed consent, those with Mini Mental State Examination (MMSE) $\geq 24^{30}$. The exclusion criteria included were those not willing to give consent, patients unable to cooperate due to severe visual, hearing, language and cognitive impairment, dementia, delirium and patients with already diagnosed psychiatric illness. MINI plus ${ }^{31}$ was used for psychiatric diagnosis. Stressful life events were assessed using PSLES. ${ }^{32}$

\section{Statistical Analysis}

Statistical analysis was done using SPSS version. Descriptive statistic tools will be used to assess mean, median, standard deviation, percentage. Categorical variables will be analyzed using Chi-square test. $\mathrm{P}$ value $<0.05$ will be considered clinically significant. Association of stressful life events with psychiatric morbidity was studied in the above sample. Ethical clearance was obtained for the study.

\section{RESULTS}

Among the study population, $50.6 \%(\mathrm{~N}=133)$ were males and $49.4 \%(\mathrm{~N}=130)$ were females. $78.7 \%$ belonged to age group $60-69,18.6 \%$ in $70-79$ age group, and $2.7 \%$ belonged to more than 80 age group. $85.2 \%(\mathrm{~N}=224)$ had a primary level of education. $65 \%(\mathrm{~N}=171)$ were unemployed and $59.3 \%$ $(\mathrm{N}=156)$ belonged to lower middle socioeconomic class. $80.2 \% 9(\mathrm{~N}=211)$ were living with spouse. $85.9 \%(\mathrm{~N}=226)$ were married and $12.9 \%(\mathrm{~N}=34)$ were widowed. In the study population, $30.8 \%(\mathrm{~N}=81)$ had a family history of psychiatric illness, $15.6 \% \quad(\mathrm{~N}=44)$ had a family history of suicide. Comorbid physical illness was found in $20.2 \%(\mathrm{~N}=53)$.

\begin{tabular}{|c|c|c|}
\hline Sex & Count & Percent \\
\hline Male & 133 & 50.6 \\
\hline Female & 130 & 49.4 \\
\hline \multicolumn{3}{|l|}{ Occupation } \\
\hline Unemployed & 171 & 65.0 \\
\hline Skilled & 65 & 24.7 \\
\hline Semiskilled & 18 & 6.9 \\
\hline Professional & 9 & 3.4 \\
\hline \multicolumn{3}{|l|}{ Religion } \\
\hline Hindu & 128 & 48.7 \\
\hline Christian & 77 & 29.3 \\
\hline Others & 58 & 22 \\
\hline \multicolumn{3}{|l|}{ Marital status } \\
\hline Single & 3 & 1.1 \\
\hline Married & 226 & 86 \\
\hline Widowed & 34 & 12.9 \\
\hline \multicolumn{3}{|l|}{ Family type } \\
\hline Nuclear & 235 & 89.3 \\
\hline Joint & 21 & 8.0 \\
\hline Extended & 7 & 2.7 \\
\hline \multicolumn{3}{|l|}{ Background } \\
\hline Rural & 78 & 29.7 \\
\hline Semi urban & 185 & 70.3 \\
\hline \multicolumn{3}{|c|}{ Table 1. Sociodemographic Data } \\
\hline
\end{tabular}

The most common psychiatric diagnosis was found to be depression $(43 \%, \mathrm{~N}=113)$. Second common was substance use disorder $(16.7 \%, \mathrm{~N}=44)$ which was divided as substance dependence and abuse. Substance most commonly used was nicotine and alcohol, of which nicotine was common. Third common was delusional disorder $(10.3 \%, \mathrm{~N}=27)$, followed by adjustment disorder $(9.5 \%, \mathrm{~N}=25)$, generalized anxiety disorder $(8.7 \%, \mathrm{~N}=23)$ and mixed anxiety and depressive disorder (6.8\%, $\mathrm{N}=18)$. However, when generalized anxiety disorder and mixed anxiety and depressive disorder were clubbed together under anxiety disorder $(15.5 \%, \mathrm{~N}=41)$ as both belong to the same spectrum, it becomes the second common psychiatric morbidity.

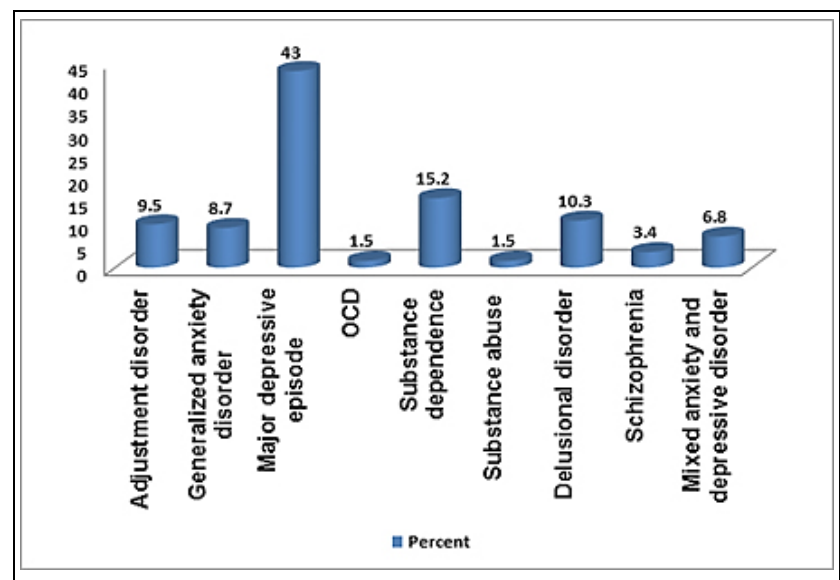

Figure 1. Percentage Distribution of the Sample According to Psychiatric Morbidity

Analysing psychiatric morbidity based on age group, depression was found to be most common among 60-69 age group, anxiety and stress related disorder (anxiety disorder and adjustment disorder were taken together for concise presentation of data and both disorders comes under the category of neurotic and stress related disorders) being common among 70-79 age group and depression being common among those more than 80 age group. Statistical 
significance was obtained showing that age has an association with development of psychiatric disorders.

\begin{tabular}{|c|c|c|c|c|c|c|c|c|}
\hline \multirow{2}{*}{$\begin{array}{l}\text { Psychiatric } \\
\text { Morbidity }\end{array}$} & \multicolumn{2}{|c|}{$60-69$} & \multicolumn{2}{|c|}{$70-79$} & \multicolumn{2}{|c|}{$>=80$} & \multirow{2}{*}{$\chi^{2}$} & \multirow{2}{*}{$\mathbf{P}$} \\
\hline & Count & $\%$ & Count & $\%$ & Count & $\%$ & & \\
\hline $\begin{array}{c}\text { Anxiety and stress related } \\
\text { disorder }\end{array}$ & 42 & 20.3 & 24.0 & 49.0 & 0 & 0.0 & \multirow{4}{*}{ 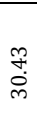 } & \\
\hline \begin{tabular}{|l|} 
Major depressive episode \\
\end{tabular} & 91 & 44.0 & 15.0 & 30.6 & 7 & 100.0 & & \\
\hline Substance use & 42 & 20.3 & 2.0 & 4.1 & 0 & 0.0 & & \\
\hline Others & 32 & 15.4 & 8.0 & 16.3 & 0 & 0.0 & & \\
\hline
\end{tabular}

Using PSLE, stressful life events that occurred anytime 1 yr. prior to the development of mental health problems were assessed. The most common stressful life event was found to be family conflict (9.5\%), second was son or daughter leaving home $(8.7 \%)$ and third was financial problems and death of spouse $(6.5 \%)$.

\begin{tabular}{|c|c|c|}
\hline Family and Social Events & Count & Percent \\
\hline Excessive alcohol use by family members & 6 & 2.3 \\
\hline Son or daughter leaving home & 23 & 8.7 \\
\hline Prophecy of astrologer or palmist & 2 & 0.8 \\
\hline Lack of son & 3 & 1.1 \\
\hline Family conflict & 25 & 9.5 \\
\hline Change of residence & 4 & 1.5 \\
\hline Financial events & & \\
\hline Financial & Count & Percent \\
\hline Financial loss or problems & 17 & 6.5 \\
\hline Robbery or theft & 1 & 0.4 \\
\hline Bereavement events & & \\
\hline Bereavement & Count & Percent \\
\hline Death of spouse & 17 & 6.5 \\
\hline Death of dose family member & 5 & 1.9 \\
\hline Table 3. Stressful Life Events Based on PSLE \\
\hline
\end{tabular}

In the present population study, $37.6 \%$ of the population experienced a stressful life event in the proceeding $1 \mathrm{yr}$. An attempt was made to study the relationship of life events in precipitating mental health problems. It was found that depression (44.4\%) was the most common psychiatric morbidity precipitated by life events, followed by anxiety and stress related disorders $(22.2 \%)$ (Anxiety disorder and adjustment disorder were clubbed together) and substance use disorders (18.2\%). No statistical significance was obtained $(\mathrm{p}<0.05)$.

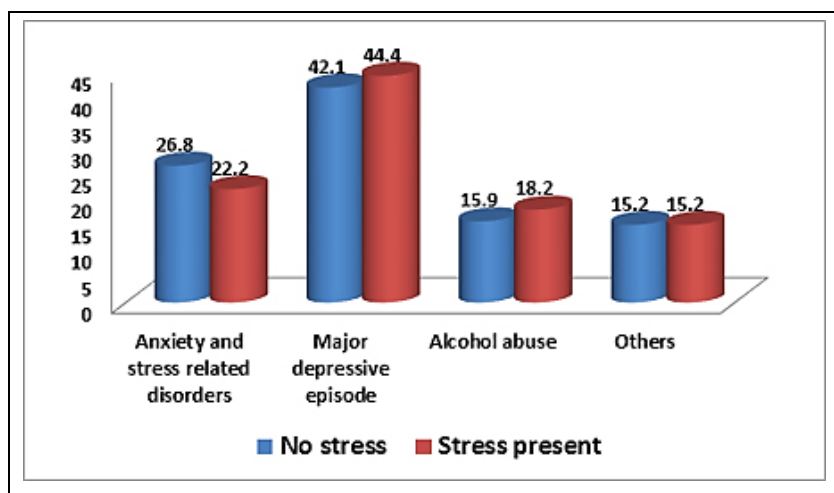

Figure 2. Comparison of Stressful Life Events Based on Psychiatric Morbidity

\section{DISCUSSION}

\section{Geriatric Psychiatric Morbidity}

In our study, maximum number of patients were in the age group of $60-69$, followed by $70-79$ and those more than 80
Depression was found to be the most common in 60-69 age group, followed by an equal prevalence of anxiety disorders and substance use disorders. While anxiety and stress related disorder was found to be most common among age group 70 79 , and depression in those more than $80 \mathrm{yrs}$. with statistical significance. As age advances, various factors like living conditions, financial difficulties, loneliness, comorbid physical illness and decreased ambulation all contribute to the development of psychiatric morbidity. As per our study, it was found that depression (43\%) was the most common psychiatric morbidity in elderly population. Second common was found to be substance use disorder $(16.7 \%)$ followed by anxiety disorder (15.5\%), when generalized anxiety disorder and mixed anxiety and depressive disorder were taken together. This corroborates with other western and Indian studies. In Schuckit et al (1975) ${ }^{33}$ who conducted a hospitalbased study in those above 65 yrs. found that depression and alcohol-related disorders were predominant. Katon and Sullivan et al (1990) on analysing found that $11 \%$ of medical in-patients had depression compared with $3 \%$ prevalence in general population. ${ }^{4}$ This could be because of associated physical comorbidity which can precipitate depression. Uwake et al (2000), 6 who evaluated patients aged more than 60 years admitted in non-psychiatric wards in a teaching hospital, found that $45.3 \%$ of the patients had psychiatric illness, with depression and anxiety disorders being common. But only $2.8 \%$ of it were recognized by physicians and sought to treatment. Similarly, in our study, it was found that medical in-patients with psychiatric morbidity were not adequately diagnosed and treated.

Among Indian studies, those of Tiwari and Srivastava et al $(1998)^{34}$, found psychiatric disorders to be prevalent in geriatric population (42.21\%) with depression and anxiety being common. Similarly, Dey et al (2010), Tiwari et al (2012), Ganguli et al (1999), also found depression to be the most common psychiatric morbidity. ${ }^{21,19,22}$ In Prasad KM et al (1996)study found non organic psychoses to be common. 35 However, according to Neethu et al (2016) organic causes like dementia, delirium was found to be common psychiatric disorder followed by mood disorder and schizophrenia. ${ }^{36} \mathrm{But}$ our study does not correlate with this as organic conditions like delirium and dementia were excluded from the study. As per Silva et al (2002) ${ }^{37}$ and Manhas et al (2019) ${ }^{38}$ also concluded that depression was the commonest psychiatric morbidity.

\section{Stressful Life Events and Geriatric Psychiatric Morbidity}

The most common stressful life event was found to be family conflicts $(9.5 \%, \mathrm{~N}=25)$. Second common being son or daughter leaving home $(8.7 \%, \mathrm{~N}=23)$. Third common being death of spouse and financial problems $(6.5 \%, \mathrm{~N}=17)$. According to Om Prakash et al (2007) ${ }^{9} 18 \%$ subjects had depression and $11 \%$ had other mental disorders. In the above study, those with mental disorders had suffered more recent stressful life events, the most reported being conflicts in family $(16 \%)$ which correlates with our study as well. The second most common life event associated was unemployment in some of the studies, though such findings were not obtained in our study. Since a majority of our study group was living with spouse $(80.2 \% \mathrm{~N}=211)$, this could correlate why in our study son or daughter leaving home was the second most common cause. According to Finlay Jones et 
al (1981) severe loss was a causal agent in the onset of depressive disorder and severe danger was a precipitating factor in the onset of anxiety states in the sample. ${ }^{39}$ The relationship between recent loss and depression has been validated in other studies as well. (Parkes, 1964; Sethi, 1964; Paykel et al., 1969). ${ }^{40,41}$ In our study significant loss in the form of death of spouse was found to be third most common. This could be because the number of widowed people in the study population is 34 (12.9\%), among whom the life event occurring in the preceding year was $6.5 \%(\mathrm{~N}=17)$. In our study, majority of the stressful life event was associated with depression (44.4\%), followed by anxiety and stress related disorders $(19.2 \%, \mathrm{~N}=23)$ and substance use disorders $(18.2 \%, \mathrm{~N}=18)$ which corroborates with above studies with respect to depression being the most common psychiatric disorder precipitated by life event.

\section{Limitations}

As it is a hospital based cross-sectional study, the results cannot be generalised. This study had a smaller sample size. Absence of a control group in the study was a drawback. All patients were screened in a one-stage interview. Coping strategies and resilience of various individuals which may affect the response to stressful life events which again may be coloured by personality traits were not analysed. Patients with cognitive impairment like dementia were not included in the study. Stressful life events of previous $1 \mathrm{yr}$. were considered for the study.

\section{CONCLUSIONS}

The development of health services has definitely contributed to life expectancy of the elderly. This increases the risk and prevalence of psychiatric morbidity in them. Elderly people are at an increased need of dependent care, social support, medical care, safety and ambulatory measures. Hence this population is at risk of developing mental health problems, often precipitated by life events. This in turn affects the quality of life of the elderly which further deteriorates their baseline functioning. Hence this study tries to emphasize the need for increasing awareness of mental health problems in the public, caretakers and medical professionals as well as early recognition and management of mental health problems in the elderly so as to improve the quality of life.

\section{REFERENCES}

[1] United Nations Population Division (UN). World Population Prospects: The 2010 Revision. New York: United 2011. http://www.esa.un.org/unpd/wpp/index.htm.

[2] Rao STS, Shaji KS. Demographic aging: implications for mental health. Indian J Psychiatry 2007;49(2):78-80.

[3] Ghosh AB. Psychiatry in India: need to focus on geriatric psychiatry. Indian J Psychiatry 2006;48(1):49.
[4] Katon W, Sullivan MD. Depression and chronic medical illness. J Clin Psychiatry 1990;Suppl 51:3-11, discussion 12-4.

[5] Katz IR, Alexopoules GS. Diagnosis and treatment of depression in late life N.I.H. Consensus statement. Am J Psychiatry 1996;4:4.

[6] Uwakwe R. Psychiatric morbidity in elderly patients admitted into non psychiatric wards in a teaching hospital in Nigeria. Int J Geriatr Psychiatry 2000;15(4):346-54.

[7] Lenze EJ, Mulsant BH, Shear MK, et al. Comorbid anxiety disorders in depressed elderly patients. Am J Psychiatry 2000;157(5):722-8.

[8] Raue PJ, Alexopoulos GS, Bruce ML, et al. The systematic assessment of depressed elderly primary care patients. Int J Geriatr Psychiatry 2001;16(6):5609.

[9] Prakash 0, Gupta LN, Singh VB, et al. Profile of psychiatric disorders and life events in medically ill elderly: experiences from geriatric clinic in Northern India. International Journal of Geriatric Psychiatry 2007;22(11):1101-5.

[10] Abraham VJ, Abraham S, Jacob KS. Suicide in the elderly in Kaniyambadi block, Tamil Nadu, South India. International Journal of Geriatrics Psychiatry 2005;20(10):953-5.

[11] Behera C, Rautji R, Sharma RK. Suicide in elderly: a study in South Delhi (1996-2005). Indian Journal of Forensic Medicine and Toxicology 2007;1(2):13-8.

[12] Rao AV, Madhavan T. Depression and suicide behaviour in the aged. Indian Journal of Psychiatry 1983;25(4):251-9.

[13] Rao VA. Suicide in the elderly. Indian Journal of Social Psychiatry 1985;1:3-10.

[14] Goswami A, Reddaiah VP, Kapoor SK, et al. Tobacco and alcohol use in rural elderly Indian population. Indian Journal of Psychiatry 2005;47(4):192-7.

[15] Jotheeswaran AT, Williams JD, Prince MJ. Predictors of mortality among elderly people living in a south Indian urban community: a 10/66 Dementia Research Group prospective population-based cohort study. BioMed Central Public Health 2010;10:366.

[16] Shaji KS, Kishore ANR, Lal KP, et al. Revealing a hidden problem: an evaluation of a community dementia case-finding program from the Indian 10/66 dementia research network. International Journal of Geriatric Psychiatry 2002;17(3):222-5.

[17] Mohan D, Chopra A, Sethi H. The co-occurrence of tobacco and alcohol in general population of metropolis Delhi. Indian Journal of Medical Research 2002;116:150-4.

[18] Gupta PC, Saxena S, Pednekar MS, et al. Alcohol consumption among middle-aged and elderly men: a community study from western India. Alcohol and Alcoholism 2003;38(4):327-31.

[19] Tiwari SC, Pandey NM, Singh I. Mental health problems among inhabitants of old age homes: a preliminary study. Indian Journal of Pyshicatry 2012;54(2):144-8.

[20] Seby K, Chaudhury S, Chakraborty R. Prevalence of psychiatric and physical morbidity in an urban geriatric population. Indian Journal of Psychiatry 2011;53(2):121-7. 
[21] Dey AB, Soneja S, Nagarkar KM, et al. Evaluation of the health and functional status of older Indians as a prelude to the development of a health programme. National Medical Journal of India 2001;14(3):135-8.

[22] Ganguli M, Dube S, Johnston JM, et al. Depressive symptoms, cognitive impairment and functional impairment in a rural elderly population in India: a Hindi version of the geriatric depression scale (GDS$\mathrm{H})$. International Journal of Geriatric Psychiatry 1999;14(10):807-20.

[23] Reddy MV, Chandrashekhar CR. Prevalence of mental and behavioural disorders in India: a meta-analysis. Indian Journal of Psychiatry 1998;40(2):149-57.

[24] Poongothai S, Pradeepa R, Ganesan A, et al. Prevalence of depression in a large urban South Indian population - The Chennai Urban Rural Epidemiology Study (CURES - 70). PLoS One 2009;4(9):e7185.

[25] Barua A, Kar N. Screening for depression in elderly Indian population. Indian Journal of Psychiatry 2010;52(2):150-3.

[26] Tiple P, Sharma SN, Srivastava AS. Psychiatric morbidity in geriatric people. Indian J Psychiatry 2006;48(2):88-94.

[27] Thirthahalli C, Suryanarayana SP, Sukumar GM, et al. Proportion and factors associated with depressive symptoms among elderly in an urban slum in Bangalore. Journal of Urban Health 2014;91(6):106575.

[28] Rao AV, Madhavan T. "Late paraphrenia" (a report from geropsychiatric clinic, Madurai, India). Indian Journal of Psychiatry 1981;23(4):291-7.

[29] Agrawal N, Jhingan HP. Life events and depression in elderly. Indian J Psychiatry 2002;44(1):34-40.

[30] Folstein MF, Folstein SE, McHugh PR. "Mini-mental state". A practical method for grading the cognitive state of patients for the clinician. Journal of Psychiatric Research 1975;12(3):189-98.
[31] Sheehan DV, Lecrubier Y, Sheehan KH, et al. The MiniInternational Neuropsychiatric Interview (M.I.N.I.): the development and validation of a structured diagnostic psychiatric interview for DSM-IV and ICD10. J Clin Psychiatry 1998;(59 Suppl 20):22-33, quiz 34-57.

[32] Singh G, Kaur D, Kaur H. Presumptive stressful life events scale (psles) - a new stressful life events scale for use In India. Indian J Psychiatry 1984;26(2):10714.

[33] Schuckit MA, Muller PL, Hahlbohm HD. Unrecognized psychiatric illness in elderly medical-surgical patients. J Gerontol 1975;30(6):655-60.

[34] Tiwari SC, Srivastava S. Geropsychiatric morbidity in rural Uttar Pradesh. Indian J Psychiatry 1998;40(3):266-73.

[35] Prasad KM, Sreenivas KN, Ashok MV, et al. Psychogeriatric patients-a sociodemographic and clinical profile. Indian Journal of Psychiatry 1996;38(3):178-81.

[36] Neethu S, Indu PV, Anil P. Profile of patients attending psychogeriatric clinic in a tertiary care setting. Indian J Psychol Med 2016;38(5):404-7.

[37] Pereira SYD, Estibeiro A, Dhume R, et al. Geriatric patients attending tertiary care psychiatric hospital. Indian J Psychiatry 2002;44(4):326-31.

[38] Manhas RS, Manhas GS, Manhas A, et al. Psychiatric morbidity among geriatric patients attending psychiatric OPD of tertiary care hospital. Journal of Medical Science and Clinical Research 2019;7(6):4917.

[39] Finlay-Jones R, Brown GW. Types of stressful life event and the onset of anxiety and depressive disorders. Psychological Medicine 1981;11(4):803-15.

[40] Sethi B. Relationship of separation to depression. Archives of General Psychiatry 1964;10(5):486-96.

[41] Paykel ES, Myers JK, Dienelt MN, et al. Life events and depression. Archives of General Psychiatry 1969;21(6):753-60. 